\title{
Diagnostic analysis of vertical orbital dystopia and canthal tilt for surgical correction
}

\author{
Ju-Young Lee ${ }^{1,3, \star}$, Han-Wool Choung ${ }^{2, *}$, Pill-Hoon Choung ${ }^{3}$ \\ ${ }^{1}$ Department of Oral and Maxillofacial Surgery, Seoul St. Mary's Hospital, ${ }^{2}$ Department of Oral and Maxillofacial Surgery, \\ Chung-Ang University Hospital, ${ }^{3}$ Department of Oral and Maxillofacial Surgery, Dental Research Institute, \\ School of Dentistry, Seoul National University, Seoul, Korea
}

\begin{abstract}
J Korean Assoc Oral Maxillofac Surg 2020;46:379-384)
Objectives: We sought to identify a clinically useful method of analyzing orbital dystopia to aid in diagnosis and treatment planning and to quantify vertical discrepancies in eye level and variations in canthal tilt in Koreans.

Patients and Methods: In 76 Korean patients with a mean age of 23.12 years, mean differences in the level of the pupils, lateral canthi, medial canthi, and canthal tilt were measured. The difference in pupil level was calculated from the perpendicular lines drawn from the midpupil area of each eye to the midline of the face to determine the amount of skeletal discrepancy of the eye. Soft tissue discrepancies were determined according to the vertical difference between the lines drawn from the lateral or medial canthus of each eye perpendicular to the midline of the face. The canthal tilt was determined from the inclination of a line connecting the lateral and medial canthi, then classified as class I, II, or III.

Results: Mean differences in pupil level, medial canthi, and lateral canthi were $1.57 \pm 1.10 \mathrm{~mm}, 1.14 \pm 1.07 \mathrm{~mm}$, and $2.03 \pm 1.64 \mathrm{~mm}$, respectively. The mean degree of canthal tilt were $8.45^{\circ} \pm 3.53^{\circ}$ for the right side and $8.42^{\circ} \pm 3.81^{\circ}$ for the left side. No study participants presented with class III canthal tilt. The mean canthal tilt values for those with class I tilt were $3.21^{\circ} \pm 1.68^{\circ}$ for the right side and $3.18^{\circ} \pm 1.63^{\circ}$ for the left side, while, for those who had class II tilt, the values were $9.60^{\circ} \pm 3.66^{\circ}$ for the right side and $9.54^{\circ} \pm 2.99^{\circ}$ for the left side.

Conclusion: The presented diagnostic method of orbital dystopia can be used to effectively establish a treatment plan that takes into consideration the patient's skeletal and soft-tissue discrepancies.
\end{abstract}

Key words: Orbit, Facial asymmetry, Anthropometry

[paper submitted 2020. 5. 18 / revised 1st 2020. 7. 2, 2nd 2020. 8. 10 / accepted 2020. 8. 10]

\section{Introduction}

Facial asymmetry is a trait that almost everyone has to some degree. It is generally assessed using horizontal and vertical reference lines ${ }^{1}$. In some patients, the median sagittal or mid-pupillary line is utilized as a reference line. When analyzing the midface and lower face, vertical reference lines

\section{Pill-Hoon Choung}

Tooth Bioengineering Laboratory, Department of Oral and Maxillofacial Surgery, Dental Research Institute, School of Dentistry, Seoul National University, 101 Daehak-ro, Jongno-gu, Seoul 03080, Korea

TEL: +82-2-740-8717 FAX: +82-2-745-7798

E-mail: smilemaker1@naver.com

ORCID: https://orcid.org/0000-0002-6763-0491

*These authors contributed equally to this work as first authors.

(c) This is an open-access article distributed under the terms of the Creative Commons Attribution Non-Commercial License (http://creativecommons.org/ licenses/by-nc/4.0/), which permits unrestricted non-commercial use, distribution, and reproduction in any medium, provided the original work is properly cited.

Copyright (O) 2020 The Korean Association of Oral and Maxillofacial Surgeons. All rights reserved. are typically used $\mathrm{d}^{2-6}$. There are many published studies on the management of asymmetry in the lower two-thirds of the face. However, available research on the diagnosis, including appropriate classification schemes for the condition, and treatment planning of asymmetry in relation to the horizontal reference line in the upper one-third of the face is limited.

Orbital dystopia, a common feature found in patients with facial asymmetry, refers to a degree of unevenness of the orbit that causes malposition of the orbital cavity in at least one of the three-dimensional planes ${ }^{7}$. The diagnosis and management of horizontal orbital dystopia, more generally known as hypertelorism, has been discussed in many studies ${ }^{8-15}$. However, there is a lack of published literature concerning vertical orbital dystopia, which is defined as a condition in which the whole orbits are not both positioned at the same horizontal level ${ }^{15}$. It is frequently present in patients with pathological conditions such as craniofaciocervical scoliosis complex, craniosynostosis, facial clefting syndromes, or a history of 
trauma or tumors ${ }^{7,16}$. Vertical orbital dystopia can also be present in the absence of pathology, but it is usually so mild in this case that affected patients are often unaware of the discrepancy. This subtle degree of vertical difference is probably even more common than the orbits sharing the same horizontal plane, yet there are patients who tend to be more aware of even slight discrepancies. Another characteristic contributing to the asymmetry of the upper one-third of the face is the degree of canthal tilt or palpebral fissure inclination. Therefore, an evaluation of the differences in canthal tilt is critical and should be used as a supplementary diagnostic method in the management of orbital dystopia.

Few reports on the management of vertical orbital dystopia exist and a standardized method of analysis has not been established yet. Also, since vertical discrepancy in the level of the eyes is also reportedly common in otherwise normal patient populations, defining the normal range of discrepancy is clinically significant. Therefore, the present study sought to (i) suggest a new method of diagnosing vertical orbital dystopia using photographic analysis and (ii) quantify vertical discrepancies in the eye levels and variations in canthal tilt.

\section{Patients and Methods}

\section{Patients}

The study was exempted from review by the Institutional

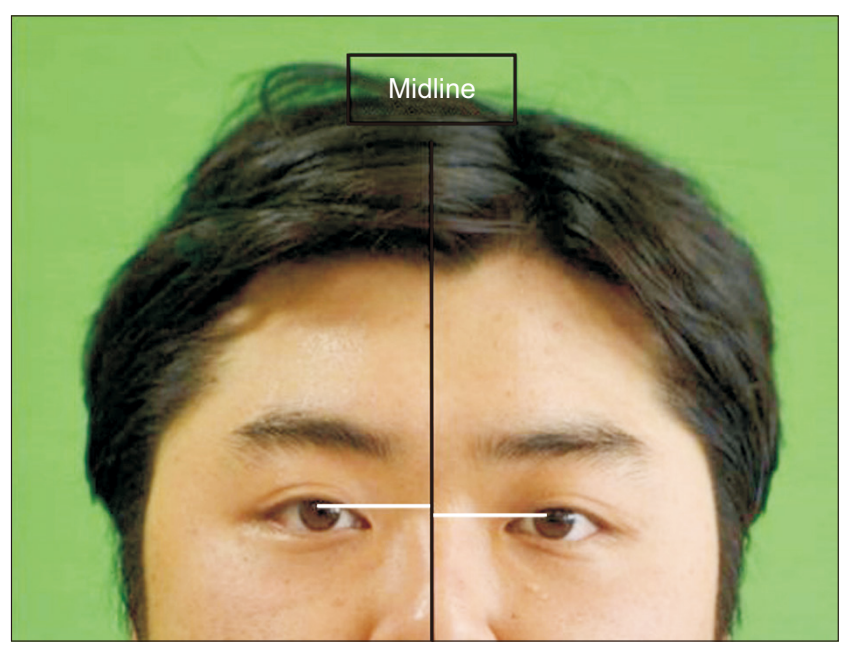

Fig. 1. Analysis of skeletal vertical discrepancy using the differences in the levels of orbits. A horizontal line (white line) from midpupil perpendicular to the midline of the face (black line) was drawn, and the differences between the horizontal lines from each side of the eyes were calculated.

Ju-Young Lee et al: Diagnostic analysis of vertical orbital dystopia and canthal tilt for surgical correction. J Korean Assoc Oral Maxillofac Surg 2020
Review Board of Seoul National University Dental Hospital (IRB No. ERI20016), and the informed consent was waived.

Seventy-six patients (45 male and 31 female patients) who presented to the Department of Oral and Maxillofacial Surgery at Seoul National University Dental Hospital from January 2013 to August 2017 with the chief complaint of facial asymmetry were analyzed in this study. The age of the study participants ranged from 13 to 38 years old, with a mean age of $23.12 \pm 5.23$ years old (female, $22.65 \pm 5.61$ years old; male, $23.44 \pm 4.99$ years old). Patients with craniofaciocervical scoliosis complex, craniofacial anomalies, a history of trauma to the eyes, tumor, or craniomaxillofacial surgery were excluded.

\section{Anthropometric measurements and photographic analysis}

Because the orbital structures are quite small and eye movements, such as blinking, are uncontrollable, taking measurements directly from patients is considered less accurate. Therefore, indirect measurements using standardized photographs were collected to investigate the differences between the levels of orbits, medial and lateral canthi, and canthal tilt. The frontal view photographs were taken (D90; Nikon, Tokyo, Japan) from a distance of $1.5 \mathrm{~m}$ with study participants in the natural head position, as previously described ${ }^{2}$. The study participants were instructed to gaze forward so that the

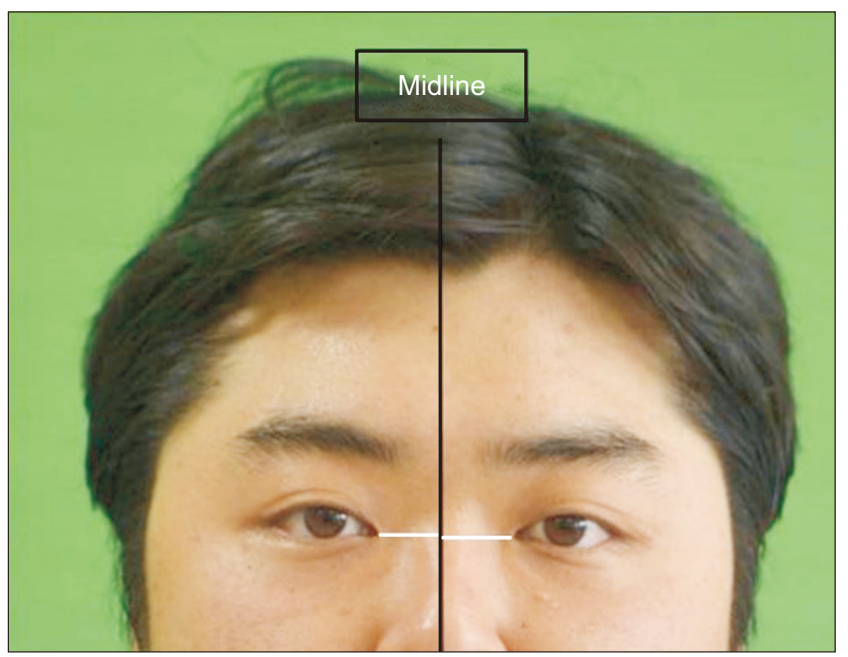

Fig. 2. Analysis of soft tissue discrepancy using the differences in the levels of medial canthi. A horizontal line (white line) from medial canthus perpendicular to the midline of the face (black line) was drawn, and the differences between the horizontal lines from each side of the eyes were calculated.

Ju-Young Lee et al: Diagnostic analysis of vertical orbital dystopia and canthal tilt for surgical correction. J Korean Assoc Oral Maxillofac Surg 2020 
porion and the inferior orbital rim were on the same horizontal plane ${ }^{2}$.

For evaluating the vertical discrepancies between the eyes, the levels of orbits, medial canthi, and lateral canthi were measured. First, the levels of orbits were analyzed by drawing a horizontal line from the midpupil area perpendicular to the midline of the face (nasion to midpoint interpupillary line $)^{17}$ and calculating the differences between the horizontal lines drawn from each side of the eyes.(Fig. 1) Then, the levels of medial canthi were compared by drawing a horizontal line from the medial canthus of each eye perpendicular to the midline of the face and calculating the differences between the horizontal lines drawn from each side of the eyes.(Fig. 2) Finally, the levels of lateral canthi were analyzed using

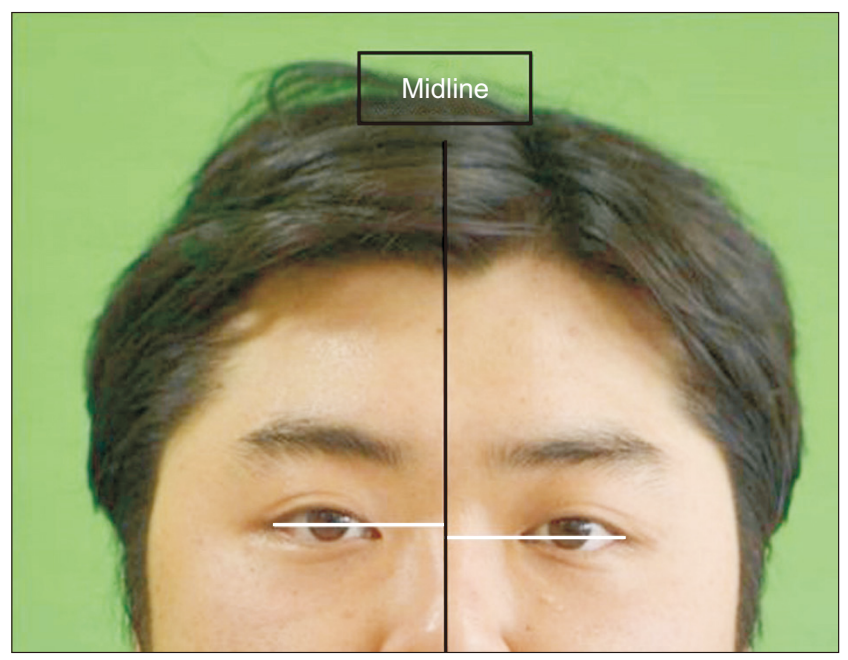

Fig. 3. Analysis of soft tissue discrepancy using the differences in the levels of lateral canthi. A horizontal line (white line) from lateral canthus perpendicular to the midline of the face (black line) was drawn, and the differences between the horizontal lines from each side of the eyes were calculated.

Ju-Young Lee et al: Diagnostic analysis of vertical orbital dystopia and canthal tilt for surgical correction. J Korean Assoc Oral Maxillofac Surg 2020

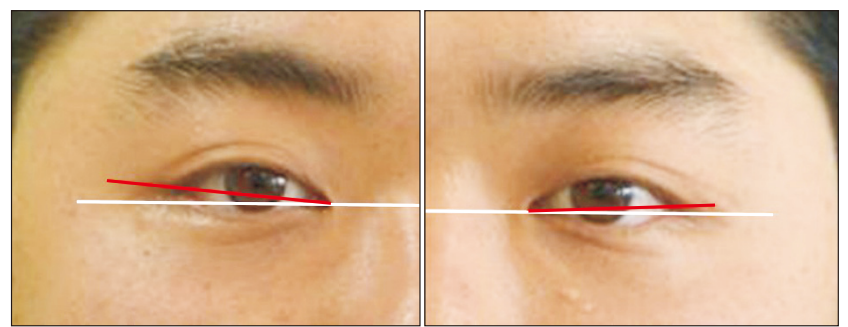

Fig. 4. Measurement of canthal tilt using an angle formed by a line connecting the medial canthus and lateral canthus (red line) and a perpendicular line (white line) connecting the medial canthus and the midline of the face (black line).

Ju-Young Lee et al: Diagnostic analysis of vertical orbital dystopia and canthal tilt for surgical correction. J Korean Assoc Oral Maxillofac Surg 2020 the same method as above, except that a horizontal line was drawn from the lateral canthus perpendicular to the midline of the face.(Fig. 3)

For the assessment of asymmetry in eyes using canthal tilt, an angle formed by a line connecting the medial canthus and the lateral canthus and a perpendicular line connecting the medial canthus and the midline of the face were measured. (Fig. 4) Then, the criteria for classifying the various canthal tilts were applied. When the canthal tilt was between $0^{\circ}$ and $5^{\circ}$, the participant was considered to have class I canthal tilt; those with canthal tilt of more than $5^{\circ}$ were categorized as having class II canthal tilt; and those with canthal tilt under $0^{\circ}$ were categorized as having class III tilt.(Fig. 5)

The calculations and statistical analyses were performed using the IBM SPSS Statistics for Windows (ver. 23; IBM, Armonk, NY, USA) and $P$-values of less than 0.05 were regarded as statistically significant.

\section{Results}

The mean values of the vertical discrepancies are listed in

Class II

(Canthal tilt $>5^{\circ}$ )
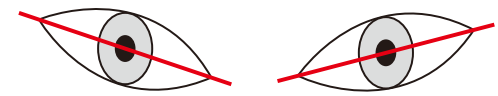

Class I

(Canthal tilt $\geq 0^{\circ}$ and $\leq 5^{\circ}$ )
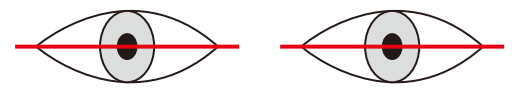

Class III

(Canthal tilt $<0^{\circ}$ )
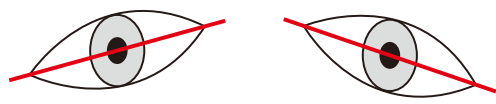

Fig. 5. Classification of canthal tilt. Criteria for classifying the various canthal tilts was applied. Class I, canthal tilt between $0^{\circ}$ and $5^{\circ}$; Class II, canthal tilt over $5^{\circ}$; Class III, canthal tilt less than $0^{\circ}$. Ju-Young Lee et al: Diagnostic analysis of vertical orbital dystopia and canthal tilt for surgical correction. J Korean Assoc Oral Maxillofac Surg 2020

Table 1. Mean values of vertical discrepancies

\begin{tabular}{lccc}
\hline \multicolumn{1}{c}{ Sex } & $\begin{array}{c}\text { Pupil }^{1} \\
(\mathrm{~mm})\end{array}$ & $\begin{array}{c}\text { Medial } \\
\text { canthus }(\mathrm{mm})\end{array}$ & $\begin{array}{c}\text { Lateral } \\
\text { canthus }(\mathrm{mm})\end{array}$ \\
\hline Female $(\mathrm{n}=31)$ & $1.40 \pm 0.78$ & $1.10 \pm 0.84$ & $2.09 \pm 1.69$ \\
Male $(\mathrm{n}=45)$ & $1.68 \pm 1.27$ & $1.17 \pm 1.22$ & $1.99 \pm 1.63$ \\
Total $(\mathrm{n}=76)$ & $1.57 \pm 1.10$ & $1.14 \pm 1.07$ & $2.03 \pm 1.64$ \\
\hline
\end{tabular}

${ }^{1}$ There was a statistically significant difference between both sexes $(P<0.05)$

Values are presented as mean \pm standard deviation.

Ju-Young Lee et al: Diagnostic analysis of vertical orbital dystopia and canthal tilt for surgical correction. J Korean Assoc Oral Maxillofac Surg 2020 
Table 1. The mean differences in the levels of the pupils, medial canthi, and lateral canthi were $1.57 \pm 1.10 \mathrm{~mm}, 1.14 \pm 1.07$ $\mathrm{mm}$, and $2.03 \pm 1.64 \mathrm{~mm}$, respectively. The differences were not statistically significant between the sexes, except for the levels of the pupils (independent-samples t-test, $P<0.05$ ).

The mean values of the degrees of canthal tilt were $8.45^{\circ} \pm 3.53^{\circ}$ for the right side and $8.42^{\circ} \pm 3.81^{\circ}$ for the left side, with female study participants showing slightly more positive degrees of canthal tilt.(Table 2) The values did not differ significantly between the two sides nor the sexes (paired-samples t-test and independent-samples t-test, $P>0.05)$.

Among the study participants, there was no case of class III canthal tilt. The mean canthal tilt values for class I study participants were $3.21^{\circ} \pm 1.68^{\circ}$ for the right side and $3.18^{\circ} \pm 1.63^{\circ}$ for the left side, while, for those in the class II group, the values were $9.60^{\circ} \pm 3.66^{\circ}$ for the right side and $9.54^{\circ} \pm 2.99^{\circ}$ for the left side.(Table 3) Generally, female participants had higher canthal tilt values than male ones in both classes, but not to a statistically significant degree (independent-samples t-test, $P>0.05$ ). Also, there were no statistically significant differences between the two sides in both classes (pairedsamples t-test, $P>0.05$ ).

\section{Discussion}

The normal craniofacial skeleton has been reported to show variable ranges of asymmetry ${ }^{18}$. Slight differences in the levels of the eyes can make facial asymmetry appear more obvious since a vertical orbital discrepancy is known to be more noticeable than the same amount of horizontal displacement ${ }^{7}$. This may motivate some overly cognizant patients to seek consultations for the correction of even minor degrees of asymmetry. However, most normal patients without pathological conditions do not require surgery. The surgical indications for vertical orbital dystopia include displacements of the orbits of more than $4 \mathrm{~mm}$, strong motivation of the patient, the presence of severe visual symptoms, and obvious facial deformity due to orbital dystopia ${ }^{7}$.

Table 2. Mean values of canthal tilt

\begin{tabular}{ccc}
\hline Sex & Right $\left(^{\circ}\right)$ & Left $\left(^{\circ}\right)$ \\
\hline Female $(\mathrm{n}=31)$ & $8.86 \pm 3.32$ & $8.89 \pm 4.10$ \\
Male $(\mathrm{n}=45)$ & $8.17 \pm 3.70$ & $8.10 \pm 3.57$ \\
Total $(\mathrm{n}=76)$ & $8.45 \pm 3.53$ & $8.42 \pm 3.81$ \\
\hline
\end{tabular}

Values are presented as mean \pm standard deviation.

Ju-Young Lee et al: Diagnostic analysis of vertical orbital dystopia and canthal tilt for surgical correction. J Korean Assoc Oral Maxillofac Surg 2020
Most oral and maxillofacial surgeons do not seem to focus much on the evaluation and management of asymmetry in the upper one-third of the face. Because orbital dystopia tends to make existing facial asymmetry more strongly apparent and severe, effective diagnosis and treatment of orbital dystopia are necessary. Thus, adopting a proper method of analysis is crucial in the management of orbital dystopia.

The treatment of orbital dystopia has ranged from camouflaging procedures for minor deformities to vertical translocation of orbits for severe deformities ${ }^{19}$. Minor corrections using camouflage procedures can be achieved by raising the eyebrow or eyelid with ptosis to provide the illusion of elevating the orbit, moving the nasion toward the affected side, medial or lateral canthopexy, or grafting of bone or alloplastic material to raise the collapsed orbit ${ }^{7}$. Osteotomies of the entire bony orbit, such as rectangular orbital osteotomies, may be required for translocation of the orbits ${ }^{19}$. These surgical methods are more technically challenging than procedures designed to correct horizontal discrepancies. In 1967, Tessier first successfully corrected vertical dystopia via a transcranial approach $^{20,21}$. Usually, an intracranial approach is used when the orbit must be raised, while an extracranial approach is necessary when the orbit needs to be moved downward.

Surgical correction of vertical orbital dystopia can lead to some serious complications, such as death due to cerebral edema $^{15}$. Other reported complications include temporary loss of vision, diplopia, percutaneous drainage of a frontal aerocele, frontal branch nerve palsy, and trismus ${ }^{15}$. Therefore, thorough diagnosis of all vertical discrepancies is necessary to avoid any unnecessary surgical procedures and complications and surgeons must be qualified to recommend the appropriate treatment for their patients. In the past, diagnosis and treatment planning to discern the amount of vertical orbital movement required were conducted by measuring lines drawn directly on the face. However, for less obvious cases of vertical asymmetry, a standardized method of analyzing

Table 3. Mean values of canthal tilt according to the canthal tilt classification

\begin{tabular}{clcc}
\hline & & Right $\left({ }^{\circ}\right)$ & Left $\left(^{\circ}\right)$ \\
\hline Class I & Female $(\mathrm{n}=4)$ & $3.71 \pm 1.80$ & $3.67 \pm 1.73$ \\
& Male $(\mathrm{n}=10)$ & $3.01 \pm 1.63$ & $2.98 \pm 1.59$ \\
Class II & Total $(\mathrm{n}=14)$ & $3.21 \pm 1.68$ & $3.18 \pm 1.63$ \\
& Female $(\mathrm{n}=27)$ & $9.92 \pm 3.53$ & $9.87 \pm 3.31$ \\
& Male $(\mathrm{n}=35)$ & $9.34 \pm 3.75$ & $9.29 \pm 2.88$ \\
& Total $(\mathrm{n}=62)$ & $9.60 \pm 3.66$ & $9.54 \pm 2.99$ \\
\hline
\end{tabular}

Values are presented as mean \pm standard deviation.

Ju-Young Lee et al: Diagnostic analysis of vertical orbital dystopia and canthal tilt for surgical correction. J Korean Assoc Oral Maxillofac Surg 2020 
the orbital discrepancies is necessary. Also, indirect analysis through photographs is more accurate in making a correct diagnosis and driving effective treatment planning. Therefore, we have quantified vertical asymmetry of the eyes and recommended applicable criteria for these asymmetries.

Among the 76 patients who presented to our hospital with the chief complaint of facial asymmetry, the mean differences in the levels of pupils, medial canthi, and lateral canthi were all less than $4 \mathrm{~mm}$, which is the criteria for a surgical indication of vertical orbital dystopia. Therefore, we could use this new analysis method to evaluate the discrepancy and plan how much surgical correction is required for patients with vertical discrepancies of more than $4 \mathrm{~mm}$. Also, we can refer to the mean values of vertical differences for postoperative evaluation of relapse and if the measurements fall under these normal ranges.

Vertical movements of the orbits may not be sufficient to achieve a symmetrical appearance of the eyes; instead, palpebral fissure inclination, or the degree of canthal tilt, may also need to be corrected. Also, in patients who do not require surgical correction of vertical orbital dystopia, minor procedures, such as medial or lateral canthopexy, can be carried out to accomplish vertical symmetries of the eyes through modifying the degree of canthal tilt. First, we classified canthal tilt into three classes. Patients with class I present a canthal tilt between $0^{\circ}$ and $5^{\circ}$; those with class II show canthal tilt of more than $5^{\circ}$; and those with class III have a canthal tilt of less than $0^{\circ}$, with the lateral canthus being more inferior than the medial canthus. According to Rhee et al. ${ }^{22}$, an attractive Korean face has a canthal tilt of $8.87^{\circ}$, which falls into the class II category. On the other hand, class III canthal tilt can make a person look old and tired and is common in the elderly population. Few studies on the asymmetry of palpebral fissure to date have been performed in the past and have only analyzed the Caucasian population ${ }^{23-25}$. Therefore, evaluations of the palpebral fissure asymmetry for data-gathering purposes is necessary in the Asian population. In a study by Song et al. ${ }^{26}$, asymmetry of the palpebral fissure was evaluated in Korean patients and the criterion for asymmetry in canthal tilt was a difference of $2^{\circ}$ between the right and the left sides. According to this criterion, the asymmetry of canthal tilt was not significant in our study since the variation between the right and the left eyes was less than $2^{\circ}$ in all cases. Also, due to the age of our study participants, most had class II canthal tilt, with values of $9.60^{\circ} \pm 3.66^{\circ}$ for the right eye and $9.54^{\circ} \pm 2.99^{\circ}$ for the left eye, suggesting the presence of attractive canthal tilt as reported in a previous study ${ }^{22}$.

However, the mean values measured in our study may not be accurately representative of the young Korean population due to the relatively small number of patients included in our study. Therefore, investigations with larger sample sizes are required in the future to produce more reliable results.

\section{Conclusion}

Evaluation of the asymmetry of the eyes in relation to the horizontal reference line should be the first step in the assessment of a patient's face; then, the vertical reference lines are used in the evaluation. However, no studies on the classification or reporting standardized analysis method for the diagnosis of asymmetry in the upper one-third of the face exist, to our knowledge. Therefore, we presented in this study a new method of analysis that can be used to evaluate asymmetry between the eyes. The new diagnostic method of orbital dystopia and mean values of vertical discrepancies and canthal tilt in Koreans can be used to effectively establish a treatment plan that takes into consideration the patient's skeletal and soft-tissue discrepancies. The correction of orbital dystopia is a fundamental procedure that needs to be carried out to achieve overall facial harmony. The details of the surgical procedures will be discussed in a future report.

\section{ORCID}

Ju-Young Lee, https://orcid.org/0000-0001-5285-767X

Han-Wool Choung, https://orcid.org/0000-0001-8134-0151

Pill-Hoon Choung, https://orcid.org/0000-0002-6763-0491

\section{Authors' Contributions}

J.Y.L. participated in data collection and wrote the manuscript. J.Y.L. and P.H.C. participated in the study design and performed the statistical analysis. H.W.C. and P.H.C. participated in the study design and coordination and helped to draft the manuscript. All authors read and approved the final manuscript.

\section{Ethics Approval and Consent to Participate}

The study was exempted from review by the Institutional Review Board of Seoul National University Dental Hospital (IRB No. ERI20016), and the informed consent was waived. 


\section{Consent for Publishing Photographs}

Written informed consent was obtained from the patient for publication of this article and accompanying images.

\section{Conflict of Interest}

No potential conflict of interest relevant to this article was reported.

\section{References}

1. Choi KY. Analysis of facial asymmetry. Arch Craniofac Surg 2015;16:1-10. https://doi.org/10.7181/acfs.2015.16.1.1

2. Song WC, Koh KS, Kim SH, Hu KS, Kim HJ, Park JC, et al. Horizontal angular asymmetry of the face in Korean young adults with reference to the eye and mouth. J Oral Maxillofac Surg 2007:65:2164-8. https://doi.org/10.1016/j.joms.2006.11.018

3. Hwang HS, Youn IS, Lee KH, Lim HJ. Classification of facial asymmetry by cluster analysis. Am J Orthod Dentofacial Orthop 2007;132:279.e1-6. https://doi.org/10.1016/j.ajodo.2007.01.017

4. Altug-Atac AT, Grayson BH, McCarthy JG. Comparison of skeletal and soft-tissue changes following unilateral mandibular distraction osteogenesis. Plast Reconstr Surg 2008;121:1751-9. https://doi. org/10.1097/PRS.0b013e31816aa003

5. Yamashita Y, Nakamura Y, Shimada T, Nomura Y, Hirashita A. Asymmetry of the lips of orthognathic surgery patients. Am J Orthod Dentofacial Orthop 2009;136:559-63. https://doi.org/10.1016/ j.ajodo.2007.10.057

6. Yu CC, Bergeron L, Lin CH, Chu YM, Chen YR. Single-splint technique in orthognathic surgery: intraoperative checkpoints to control facial symmetry. Plast Reconstr Surg 2009;124:879-86. https://doi.org/10.1097/PRS.0b013e3181b03842

7. Edgerton MT, Jane JA. Vertical orbital dystopia--surgical correction. Plast Reconstr Surg 1981;67:121-38.

8. Tan ST, Mulliken JB. Hypertelorism: nosologic analysis of 90 patients. Plast Reconstr Surg 1997;99:317-27. https://doi. org/10.1097/00006534-199702000-00004

9. Shakir S, Hoppe IC, Taylor JA. State-of-the-art hypertelorism management. Clin Plast Surg 2019;46:185-95. https://doi.org/10.1016/ j.cps.2018.11.004

10. Laure B, Batut C, Benouhagrem A, Joly A, Travers N, Listrat A, et al. Addressing hypertelorism: indications and techniques. Neurochirurgie 2019;65:286-94. https://doi.org/10.1016/ j.neuchi.2019.09.007

11. Batut C, Joly A, Travers N, Guichard B, Paré A, Laure B. Surgical treatment of orbital hypertelorism: historical evolution and development prospects. J Craniomaxillofac Surg 2019;47:1712-9. https://doi.org/10.1016/j.jcms.2019.07.002

12. Winters R. Tessier clefts and hypertelorism. Facial Plast Surg Clin North Am 2016;24:545-58. https://doi.org/10.1016/ j.fsc.2016.06.013
13. Engel M, Hoffmann J, Castrillon-Oberndorfer G, Freudlsperger C. The value of three-dimensional printing modelling for surgical correction of orbital hypertelorism. Oral Maxillofac Surg 2015;19:915. https://doi.org/10.1007/s10006-014-0466-1

14. Liu DL, Shan L, Yuan Q, Huang JJ. Refinement of the correction of orbital hypertelorism. J Craniofac Surg 2011;22:217-9. https:// doi.org/10.1097/SCS.0b013e3181f7604f

15. Tan ST, Ashworth G, Czypionka S, Poole MD, Briggs M. Vertical orbital dystopia. Plast Reconstr Surg 1996;97:1349-61. https://doi. org/10.1097/00006534-199606000-00004

16. Poole MD, Briggs M. The cranio-facio-cervical scoliosis complex. Br J Plast Surg 1990;43:670-5. https://doi.org/10.1016/00071226(90)90187-5

17. Kim EJ, Ki EJ, Cheon HM, Choi EJ, Kwon KH. 3-Dimensional analysis for class III malocclusion patients with facial asymmetry. J Korean Assoc Oral Maxillofac Surg 2013;39:168-74. https://doi. org/10.5125/jkaoms.2013.39.4.168

18. Cook JT. Asymmetry of the cranio-facial skeleton. Br J Orthod 1980;7:33-8. https://doi.org/10.1179/bjo.7.1.33

19. Moore FO, Thornton BP, Zabel DD, Vasconez HC. Autogenous orbital reconstruction in a child with congenital abnormalities of the orbital roof and vertical orbital dystopia. J Craniofac Surg 2004;15:930-3. https://doi.org/10.1097/00001665-20041100000008

20. Tessier P. Congenital orbital dystopias. In: Tessier P, Rougier J, Wolfe SA, eds. Plastic surgery of the orbit and eyelids. New York: Masson Publishing; 1981:191-9.

21. De Ponte FS, Fadda T, Rinna C, Brunelli A, Iannetti G. Early and late surgical treatment of orbital dystopia in craniofacial malformation. J Craniofac Surg 1997;8:17-22. https://doi. org/10.1097/00001665-199701000-00008

22. Rhee SC, Woo KS, Kwon B. Biometric study of eyelid shape and dimensions of different races with references to beauty. Aesthetic Plast Surg 2012;36:1236-45. https://doi.org/10.1007/s00266-0129937-7

23. Farkas LG. Anthropometry of the head and face. 2nd ed. New York: Raven Press; 1994:101-11.

24. Lam BL, Lam S, Walls RC. Prevalence of palpebral fissure asymmetry in white persons. Am J Ophthalmol 1995;120:518-22. https://doi.org/10.1016/s0002-9394(14)72667-4

25. Doganay F, Dadaci Z, Topcu-Yilmaz P, Doganay Aydin H. The association between ocular dominance and physiological palpebral fissure asymmetry. Laterality 2017;22:412-8. https://doi.org/10.108 0/1357650X.2016.1209212

26. Song WC, Kim SJ, Kim SH, Hu KS, Kim HJ, Koh KS. Asymmetry of the palpebral fissure and upper eyelid crease in Koreans. J Plast Reconstr Aesthet Surg 2007;60:251-5. https://doi.org/10.1016/ j.bjps.2006.04.027

How to cite this article: Lee JY, Choung HW, Choung PH. Diagnostic analysis of vertical orbital dystopia and canthal tilt for surgical correction. J Korean Assoc Oral Maxillofac Surg 2020;46:379384. https://doi.org/10.5125/jkaoms.2020.46.6.379 